\title{
PENENTUAN PRIORITAS KEGIATAN PERAWATAN BANGUNAN GEDUNG SEKOLAH NEGERI DI KOTA BLITAR
}

\author{
Ismanto $^{* 1}$, Harimurti ${ }^{2}$ dan Yulvi Zaika ${ }^{3}$ \\ ${ }^{1}$ Mahasiswa/Magister/Teknik Sipil/Universitas Brawijaya \\ ${ }^{2,3}$ Dosen//Teknik Sipil/Universitas Brawijaya \\ Korespondensi: ism.ismanto@gmail.com
}

\begin{abstract}
Performance of a building construction will decrease with increase life service of the structure. To maintain the performance building in order to remain functioning properly it is necessary to repair the damaged building components. The purpose of this study is to get an assessment the physical condition of the building and analyze damage level of school structure in Blitar City, and get the order to maintenance of elementary school structures in Blitar City. Weight of structure criteria assessed by the building expert and analyzed with Analytical Hierarchy Process (AHP) method, then the result of the weight is multiplied by the physical condition index obtained from the observation. Assessment of physical condition index of elementary school structure in Blitar city is $69.34 \%$, it can be interpreted that the structure is in deterioration or damage but does not affect the overall structure of the building.
\end{abstract}

Keyword: Analytical Hierarchy Process (AHP), Damage Level Building, Index Condition Building,

\section{PENDAHULUAN}

Bangunan sekolah merupakan salah satu fasilitas publik yang mempunyai fungsi sangat penting. Oleh karena itu bangunan sekolah perlu mendapatkan perhatian yang serius dalam hal pemeliharaan dan perawatannya. Pemerintah Kota Blitar melalui Dana Alokasi Khusus (DAK) setiap tahunnya telah menganggarkan dana untuk pemeliharaan dan perawatan bangunan sekolah. Namun jumlah sekolah yang rusak dengan kemampuan keuangan tidak seimbang, sehingga saat ini belum semua sekolah yang rusak dapat diperbaiki. Berdasarkan data dari Dinas Pendidikan Kota Blitar, saat ini di Kota Blitar terdapat 69 sekolah dari tingkat SD sampai dengan SLTA yang terdiri dari 48 sekolah dasar, 4 sekolah luar biasa, 10 sekolah menengah pertama, 4 sekolah menengah atas dan 3 sekolah menengah kejuruan. Dengan jumlah sekolah yang begitu banyak dan anggaran yang terbatas, maka sampai saat ini masih belum semua gedung sekolah dapat tertangani secara maksimal.
Untuk menangani permasalahan perawatan bangunan gedung sekolah, Dinas Pendidikan Kota Blitar menggunakan Petunjuk

Teknis mengenai Dana Alokasi Khusus (DAK) Bidang Pendidikan sesuai dengan Peraturan Direktur Jenderal Pendidikan Dasar dan Menengah No. 04/D/P/2016 tentang Petunjuk Pelaksanaan DAK Bidang Pendidikan Sekolah Dasar/Sekolah Dasar Luar Biasa, namun pada pelaksanaannya untuk menentukan prioritas perawatan bangunan gedung sekolah yang akan direhabilitasi masih terdapat kekurang tepatan karena pengidentifikasian bangunan masih dilakukan secara subjektif.

Permasalahan yang terjadi adalah pada penentuan prioritas perawatan bangunan gedung sekolah yang mana memiliki struktur yang belum jelas, ketidakpastian persepsi pengambil keputusan serta ketidakpastian tersedianya data statistik yang akurat. Sehingga diperlukan metode yang dapat memecahkan masalah yang kompleks dimana kriteria yang diambil cukup banyak. Dalam penelitian ini digunakan metode Multi Criteria Decision Making (MCDM) yang salah satu metodenya adalah Metode Analytic Hierarchy Process 
(AHP) yang dikembangkan oleh Thomas L. Saaty.

Mengingat beberapa masalah di atas maka dilakukan penelitian untuk membuat penilaian yang dapat membantu untuk menentukan skala prioritas penanganan pemeliharaan bangunan gedung sekolah di Kota Blitar.

Dari hasil penelitian ini diharapkan akan diperoleh suatu kesimpulan metode yang lebih representatif yang dapat digunakan dalam penentuan skala prioritas kegiatan penanganan infrastruktur yang lebih efektif, efisien dan tepat sasaran pada bangunan sekolah di Kota Blitar. Tujuan penelitian ini adalah mendapatkan penilaian kondisi fisik bangunan sekolah dasar negeri di Kota Blitar, dan mendapatkan urutan prioritas penanganan kegiatan perawatan bangunan sekolah dasar negeri di Kota Blitar.

\section{TINJAUAN PUSTAKA \\ 2.1 Kerusakan Bangunan}

Tidak berfungsinya kerusakan atau komponen bangunan yang diakibatkan karena penyusutan/berakhirnya umur bangunan, atau akibat ulah manusia, atau akibat perilaku alam (gempa bumi, penurunan tanah, banjir, dan lain-lain) atau akibat beban fungsi yang berlebihan, atau juga akibat pengaruh fisik/kimia/serangga dinamakan kerusakan bangunan (Permen PU No. 24, 2008). Menurut Permen PU No. 24, 2008 kerusakan bangunan dapat digolongkan menjadi 3 (tiga) tingkat kerusakan, yaitu:

1. Kerusakan ringan

a. Kerusakan ringan adalah kerusakan terutama pada komponen non-struktural, seperti penutup atap, langit-langit, penutup lantai, dan dinding pengisi.

b. Perawatan untuk kerusakan ringan kerusakan ringan, biayanya maksimum adalah sebesar $35 \%$ dari harga satuan tertinggi pembangunan bangunan gedung baru yang berlaku, untuk tipe/klas dan lokasi yang sama.

2. Kerusakan sedang

a. Kerusakan sedang adalah kerusakan pada sebagian komponen non-struktural, dan atau komponen struktural seperti struktur atap, lantai, dan lain-lain.

b. Perawatan untuk tingkat kerusakan sedang, biayanya maksimum adalah sebesar $45 \%$ dari harga satuan tertinggi pembangunan bangunan gedung baru yang berlaku, untuk tipe/klas dan lokasi yang sama.

3. Kerusakan berat

a. Kerusakan berat adalah kerusakan pada sebagian besar komponen bangunan, baik struktural maupun non-struktural yang apabila setelah diperbaiki dapat berfungsi dengan baik sebagaimana mestinya.

b. Biayanya maksimum adalah sebesar $65 \%$ dari harga satuan tertinggi pembangunan bangunan gedung baru yang berlaku untuk tipe/klas dan lokasi yang sama.

Tabel 1. Skala penilaian perbandingan pasangan

\begin{tabular}{|c|c|c|}
\hline $\begin{array}{c}\text { Intensitas } \\
\text { Kepentingan }\end{array}$ & Definisi & Penjelasan \\
\hline 1 & $\begin{array}{l}\text { Elemen yang sama } \\
\text { pentingnya } \\
\text { dibanding dengan } \\
\text { elemen yang lain } \\
\text { (Equal importance) }\end{array}$ & $\begin{array}{l}\text { Kedua elemen } \\
\text { menyumbang } \\
\text { sama besar } \\
\text { pada sifat } \\
\text { tersebut. }\end{array}$ \\
\hline 3 & $\begin{array}{l}\text { Elemen yang satu } \\
\text { sedikit lebih penting } \\
\text { daripada elemen } \\
\text { yang lain (Moderate } \\
\text { more importance) }\end{array}$ & $\begin{array}{l}\text { Pengalaman } \\
\text { menyatakan } \\
\text { sedikit } \\
\text { berpihak pada } \\
\text { satu elemen }\end{array}$ \\
\hline 5 & $\begin{array}{l}\text { Elemen yang satu } \\
\text { jelas lebih penting } \\
\text { dari pada elemen } \\
\text { yang lain (Essential, } \\
\text { Strong more } \\
\text { importance) }\end{array}$ & $\begin{array}{l}\text { Pengalaman } \\
\text { menunjukan } \\
\text { secara kuat } \\
\text { memihak pada } \\
\text { satu elemen. }\end{array}$ \\
\hline 7 & $\begin{array}{l}\text { Elemen yang satu } \\
\text { sangat jelas lebih } \\
\text { penting daripada } \\
\text { elemen yang lain } \\
\text { (Demonstrated } \\
\text { elemen) }\end{array}$ & $\begin{array}{l}\text { Pengalaman } \\
\text { menunjukan } \\
\text { secara kuat } \\
\text { disukai dan } \\
\text { dominan } \\
\text { dalam praktek }\end{array}$ \\
\hline 9 & $\begin{array}{l}\text { Elemen yang satu } \\
\text { mutlak lebih } \\
\text { penting dari elemen } \\
\text { lain (Absolutely } \\
\text { more importance) }\end{array}$ & $\begin{array}{l}\text { Pengalaman } \\
\text { menunjukan } \\
\text { satu elemen } \\
\text { sangat jelas } \\
\text { lebih penting }\end{array}$ \\
\hline
\end{tabular}

\subsection{Analitical Hierarchy Process (AHP)}

Perhitungan bobot elemen bangunan gedung dimulai dari sub elemen, elemen, komponen hingga sub bangunan gedung. Pembobotan ini diperlukan untuk menghitung indeks kondisi bangunan. Pembobotan dapat juga dilakukan dengan metode multi kriteria, yaitu dengan penilaian matriks perbandingan berpasangan (pairwise comparison matrix) berdasar metode Analytical Hierarchy Process (AHP) dengan input utamanya persepsi manusia, dimana secara naluri manusia dapat mengestimasi besaran sederhana melalui inderanya. Saaty (1991) [4] menetapkan skala 
kuantitatif 1 (satu) sampai dengan 9 (sembilan) untuk menilai perbandingan tingkat kepentingan suatu elemen terhadap yang lain, seperti ditunjukkan pada Tabel 1.

\subsection{Indeks Kondisi Fisik Bangunan}

Untuk menilai kondisi bangunan pada suatu waktu dapat dilakukan dengan menetapkan nilai indeks kondisi bangunan yang merupakan penggabungan dua atau lebih nilai kondisi komponen yang dikalikan dengan bobot komponen masing-masing. Menurut Hudson (2009), indeks kondisi gabungan (Composite Conditions Index) dirumuskan sebagai berikut:

$$
C C I=W 1 . C 1+W 2 . C 2+W 3 . C 3
$$

atau dapat dituliskan:

$$
C C I=\sum_{i=1}^{n} W i x C i
$$

dimana:

$$
\begin{array}{ll}
C C I & =\text { Indeks Kondisi Gabungan } \\
W & =\text { bobot komponen } \\
C & =\text { nilai kondisi bangunan } \\
i=1 & =\text { komponen ke-1 (satu) } \\
n & =\text { banyaknya komponen }
\end{array}
$$

Nilai indeks kondisi mempunyai skala antara 0 (nol) hingga 100 (seratus), yang menggambarkan tingkat kondisi bangunan. Indeks kondisi bernilai 0 berarti bangunan sudah tidak berfungsi dan 100 untuk bangunan yang masih dalam kondisi baik sekali. Nilai Indeks kondisi dapat digunakan sebagai dasar dalam penanganan bangunan dengan berpedoman pada Tabel 2.

Perhitungan dengan formula diatas, konstanta $\mathrm{C}$ yang digunakan bernilai 100 yang merupakan nilai maksimal penilaian sedangkan nilai pengurang besarnya antar nol hingga seratus, tergantung pada jenis kerusakan $(\mathrm{Tj})$, tingkat kerusakan $(\mathrm{Sj})$, kuantitas kerusakan (Dij). Faktor koreksi tergantung pada tingkat bahaya tiap jenis kerusakan, dengan jumlah faktor koreksi untuk semua jenis koreksi adalah satu, seperti pada Tabel 3.

Perhitungan indeks kondisi bangunan diperlukan pembobotan. Pembobotan ini dilakukan menggunakan metode multi criteria, yaitu dengan penilaian perbandingan

\begin{tabular}{|c|c|c|c|}
\hline Zone & $\begin{array}{l}\text { Indeks } \\
\text { Kondisi }\end{array}$ & Uraian Kondisi & $\begin{array}{l}\text { Tindakan } \\
\text { Penanganan } \\
\end{array}$ \\
\hline \multirow[t]{2}{*}{1} & $85-100$ & $\begin{array}{l}\text { Baik sekali: Tidak } \\
\text { terlihat kerusakan, } \\
\text { beberapa } \\
\text { kekurangan } \\
\text { mungkin terlihat. }\end{array}$ & \multirow[t]{2}{*}{$\begin{array}{l}\text { Tindakan } \\
\text { segera masih } \\
\text { belum } \\
\text { diperlukan. }\end{array}$} \\
\hline & $70-84$ & $\begin{array}{l}\text { Baik: Hanya terjadi } \\
\text { deteriorasi atau } \\
\text { kerusakan kecil. }\end{array}$ & \\
\hline \multirow[t]{2}{*}{2} & $55-69$ & $\begin{array}{l}\text { Sedang: Mulai } \\
\text { terjadi deteriorasi } \\
\text { atau kerusakan } \\
\text { namun tidak } \\
\text { mempengaruhi } \\
\text { fungsi struktur } \\
\text { bangunan secara } \\
\text { keseluruhan. }\end{array}$ & \multirow[t]{2}{*}{$\begin{array}{l}\text { Perlu dibuat } \\
\text { analisis } \\
\text { ekonomi } \\
\text { alternatif } \\
\text { perbaikan } \\
\text { untuk } \\
\text { menetapkan } \\
\text { tindakan yang } \\
\text { sesuai/tepat. }\end{array}$} \\
\hline & $40-54$ & $\begin{array}{l}\text { Cukup: Terjadi } \\
\text { deteriorasi atau } \\
\text { kerusakan tetapi } \\
\text { bangunan masih } \\
\text { cukup berfungsi. }\end{array}$ & \\
\hline \multirow[t]{3}{*}{3} & $25-39$ & $\begin{array}{l}\text { Buruk: Terjadi } \\
\text { kerusakan yang } \\
\text { cukup kritis } \\
\text { sehingga fungsi } \\
\text { bangunan terganggu }\end{array}$ & \multirow{3}{*}{$\begin{array}{l}\text { Evaluasi } \\
\text { secara detail } \\
\text { diperlukan } \\
\text { untuk } \\
\text { menentukan } \\
\text { tindakan } \\
\text { repair, } \\
\text { rehabilitasi } \\
\text { dan } \\
\text { rekonstruksi, } \\
\text { selain } \\
\text { diperlukan } \\
\text { evaluasi untuk } \\
\text { keamanan. }\end{array}$} \\
\hline & $10-24$ & $\begin{array}{l}\text { Sangat buruk: } \\
\text { Kerusakan parah } \\
\text { dan bangunan } \\
\text { hampir tidak } \\
\text { berfungsi. }\end{array}$ & \\
\hline & $0-9$ & $\begin{array}{l}\text { Runtuh: Pada } \\
\text { komponen utama } \\
\text { bangunan terjadi } \\
\text { keruntuhan. }\end{array}$ & \\
\hline
\end{tabular}
berpasangan (pairwise comparison) berdasarkan Analytical Hierarchy Process $(A H P)$ yang kemudian dikalikan dengan

\begin{tabular}{|c|c|c|c|}
\hline No & $\begin{array}{l}\text { Jumlah } \\
\text { Kombinasi } \\
\text { Kerusakan }\end{array}$ & $\begin{array}{l}\text { Prioritas } \\
\text { Bahaya } \\
\text { Kerusakan }\end{array}$ & $\begin{array}{l}\text { Faktor Koreksi } \\
\mathrm{F}(\mathrm{t}, \mathrm{d})\end{array}$ \\
\hline \multirow{2}{*}{1} & \multirow{2}{*}{2} & I & $0,8-0,7-0,6$ \\
\hline & & II & $0,2-0,3-0,4$ \\
\hline \multirow{3}{*}{2} & \multirow{3}{*}{3} & I & $0,5-0,6$ \\
\hline & & II & $0,3-0,4$ \\
\hline & & III & $0,1-0,2$ \\
\hline
\end{tabular}

masing-masing komponen pada perhitungan indeks kondisi fisik bangunan.

Tabel 2. Skala indeks kondisi

Tabel 3. Faktor koreksi untuk kombinasi kerusakan

\section{METODE PENELITIAN}

Penelitian ini menggunakan analisis deskriptif, metode Analytical Hierarchy Process (AHP dan indeks kondisi fisik bangunan. Dengan pengumpulan data melalui: 
a. Studi literatur yang bersumber dari Permen PU No.24/PRT/M/2008, Permen PU No.45/PRT/M/2007, Permendiknas No.24/ 2007, teks books tentang AHP, dan lain-lain.

b. Wawancara langsung dengan pemangku kepentingan dalam hal perawatan bangunan gedung sekolah yaitu dari Dinas Pendidikan Kota Blitar dan juga pihak sekolah.

c. Penyebaran kuesioner dan penilaian kondisi fisik bangunan melibatkan 5 (lima) responden yang dipilih secara purposive random sampling yaitu pemilihan responden berdasarkan pertimbangan dengan persyaratan responden yang dipilih memiliki pengetahuan dan kompetensi di bidang penanganan bangunan di Kota Blitar. Adapun respond expert yang dipilih terdiri dari:

- 1 (satu) orang Kepala Departemen PU,

- 1 (satu) orang Kepala Bidang Tata Ruang PU,

- 1 (satu) orang Kepala Seksi Bina Teknik dan Konstruksi PU,

- 1 (satu) orang Staff Bina Teknik dan Konstruksi PU,

- 1 (satu) orang akademisi teknik sipil.

\subsection{Tahapan Penelitian}

a. Pembuatan hierarki bangunan mulai dari bangunan menyeluruh kemudian dibagi menjadi komponen struktur, komponen arsitektur, komponen utilitas. Kemudian masing-masing sistem ini diuraikan sampai kepada komponen yang paling kecil.

b. Melakukan pembobotan komponen bangunan. Pembobotan bangunan berdasarkan tingkat kepentingan fungsi komponen masing-masing elemen terhadap sistem di atasnya dengan metode AHP.

c. Melakukan perhitungan indeks kondisi bangunan masing-masing sekolah berdasarkan data survei kondisi eksistensi masing-masing bangunan sekolah.

d. Melakukan perhitungan skala prioritas penanganan perawatan bangunan sekolah dasar negeri di Kota Blitar.

e. Menentukan skenario penanganan pemeliharaan gedung berdasarkan tingkat kerusakan bangunan yang paling tinggi.

Tahapan yang dilakukan dalam penelitian ini digambarkan pada Gambar 1.

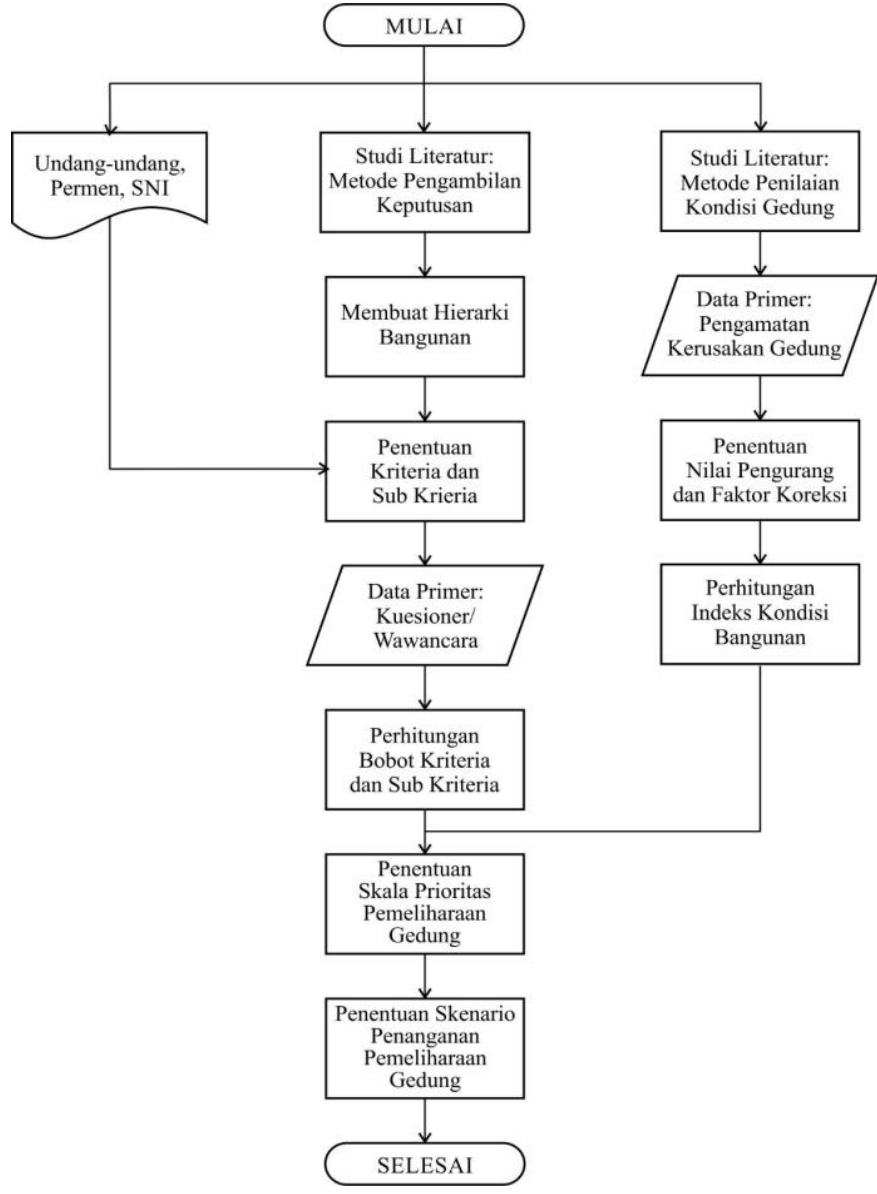

Gambar 1. Bagan alir tahapan penelitian

\subsection{Penentuan Kriteria Pembobotan}

Untuk penilaian, dilakukan pembuatan hierarki bangunan. Pembuatan hierarki bangunan mulai dari sistem bangunan menyeluruh kemudian dibagi menjadi komponen struktur, arsitektur dan utilitas, kemudian masing-masing komponen diuraikan sampai pada elemen berikutnya seperti terlihat pada Gambar 2.

Bangunan sekolah dirumuskan dengan hubungan/kepentingannya dalam bentuk hierarki. Perhitungan pembobotan secara terstruktur menggunakan metode AHP dilakukan secara bertahap per kriteria, misalnya pada pembobotan sub kriteria struktur, arsitektur dan utilitas digunakan alternatif keselamatan, kenyamanan, kesehatan dan kemudahan akses yang masing-masing dinilai tingkat kepentingannya. Berdasarkan hasil kajian, ditentukan alternatif-alternatif berikut sebagaimana dalam Tabel 4. 


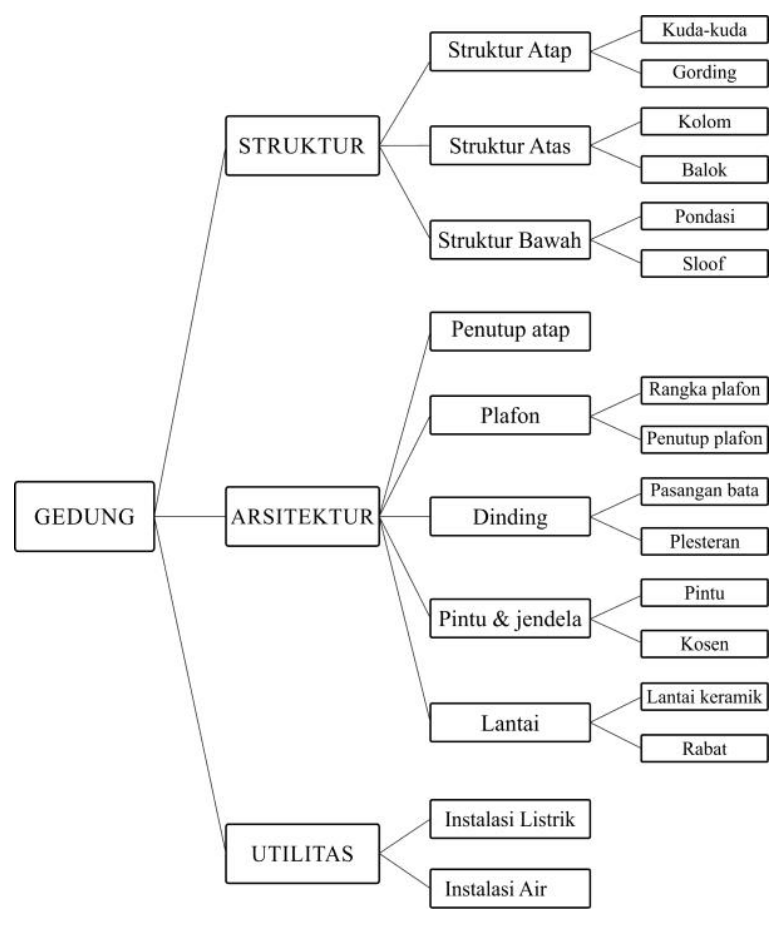

Gambar 2. Skema hierarki bangunan

\subsection{Pembobotan Kriteria}

Untuk mendapatkan bobot dari masingmasing kriteria yaitu dengan menentukan nilai eigen. Cara untuk mendapatkan bobot adalah sebagai berikut:

a. Melakukan perkalian elemen-elemen dalam satu baris dan diakar pangkat $\mathrm{n}$

$$
w_{i}=\sqrt[n]{a_{11} x a_{12} x a_{13} x \ldots \ldots a_{1 n}}
$$

b. Menghitung vektor prioritas atau eigen vector, hasil yang didapat berupa eigen vector sebagai bobot elemen.

$$
x_{1}=\frac{w_{i}}{\sum w_{i}}
$$

c. Menghitung nilai eigen maksimum $\left(\lambda_{\text {maks }}\right)$ dengan cara mengalikan matriks respirokal dengan bobot yang didapat, hasil dari penjumlahan operasi matriks adalah nilai eigen maksimum $\left(\lambda_{\text {maks }}\right)$.

$$
\lambda_{\text {maks }}=\sum a_{i j} \cdot x_{i}
$$

dengan:

$$
\begin{aligned}
\lambda_{\text {maks }}= & \text { eigen } \text { maksimum } \\
\sum a_{i j}= & \text { nilai matriks perbandingan } \\
& \text { berpasangan } \\
x_{i} & =\text { vector eigen (bobot) }
\end{aligned}
$$

d. Perhitungan indeks konsistensi, perhitungan ini untuk mengetahui konsistensi jawaban

\begin{tabular}{|c|c|c|}
\hline Kriteria & Sub Kriteria & Alternatif \\
\hline Gedung & $\begin{array}{l}\text { - Struktur } \\
\text { - Arsitektur } \\
\text { - Utilitas }\end{array}$ & $\begin{array}{l}\text { - Keselamatan } \\
\text { - Kenyamanan } \\
\text { - Kesehatan } \\
\text { - Kemudahan akses }\end{array}$ \\
\hline Struktur & $\begin{array}{ll}\text { - } & \text { Struktur atap } \\
\text { - } & \text { Struktur atas } \\
\text { - } & \text { Struktur } \\
& \text { bawah }\end{array}$ & $\begin{array}{l}\text { - Mendukung dan menyalurkan } \\
\text { beban } \\
\text { - Mendukung bentuk bangunan } \\
\text { - Mendukung kekakuan } \\
\text { struktur }\end{array}$ \\
\hline Arsitektur & $\begin{array}{ll}\text { - } & \text { Penutup atap } \\
\text { - } & \text { Plafon } \\
\text { - } & \text { Dinding } \\
\text { - } & \text { Pintu \& } \\
& \text { jendela } \\
\text { - } & \text { Lantai }\end{array}$ & $\begin{array}{l}\text { - Mendukung kenyamanan } \\
\text { aktivitas } \\
\text { - Mengatur sirkulasi udara dan } \\
\text { cahaya } \\
\text { - Melindungi dari cuaca }\end{array}$ \\
\hline Utilitas & $\begin{array}{ll}\text { - } & \text { Instalasi } \\
\text { listrik } \\
\text { - Instalasi air }\end{array}$ & $\begin{array}{ll}\text { - } & \text { Mendukung kenyamanan } \\
\text { - } & \text { Mendukung aktivitas KBM } \\
\text { - } & \text { Mendukung kebersihan dan } \\
& \text { kesehatan }\end{array}$ \\
\hline $\begin{array}{l}\text { Struktur } \\
\text { atap }\end{array}$ & $\begin{array}{l}\text { - Kuda-kuda } \\
\text { - Gording }\end{array}$ & $\begin{array}{l}\text { - Mendukung dan menyalurkan } \\
\text { beban atap } \\
\text { - Mendukung bentuk atap } \\
\text { - Memberikan kekakuan pada } \\
\text { atap }\end{array}$ \\
\hline Struktur atas & \begin{tabular}{|ll} 
- & Kolom \\
- & Balok \\
\end{tabular} & $\begin{array}{l}\text { - Mendukung dan menyalurkan } \\
\text { beban } \\
\text { - Mendukung bentuk bangunan }\end{array}$ \\
\hline $\begin{array}{l}\text { Struktur } \\
\text { bawah }\end{array}$ & $\begin{array}{ll}\text { - } & \text { fondasi } \\
\text { - Sloof }\end{array}$ & 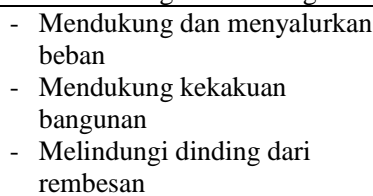 \\
\hline Plafon & $\begin{array}{l}\text { - Rangka } \\
\text { plafon } \\
\text { - Penutup } \\
\text { plafon }\end{array}$ & $\begin{array}{l}\text { - Dudukan instalasi listrik } \\
\text { - Memperindah ruangan } \\
\text { - Mencegah kotoran dan } \\
\text { meredam panas }\end{array}$ \\
\hline Dinding & $\begin{array}{l}\text { - Pasangan } \\
\text { batu-bata } \\
\text { - Plesteran }\end{array}$ & $\begin{array}{l}\text { - Melindungi bangunan dari } \\
\text { cuaca } \\
\text { - Mendukung estetika dan } \\
\text { bentuk bangunan } \\
\text { - Memberi dudukan untuk } \\
\text { kosen }\end{array}$ \\
\hline $\begin{array}{l}\text { Pintu \& } \\
\text { Jendela }\end{array}$ & $\begin{array}{l}\text { - Daun pintu \& } \\
\text { jendela } \\
\text { - Kosen } \\
\end{array}$ & $\begin{array}{l}\text { - Memberi pencahayaan alami } \\
\text { - Memberikan sirkulasi udara } \\
\text { - Memberi keindahan bangunan }\end{array}$ \\
\hline Lantai & 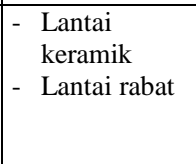 & $\begin{array}{l}\text { - Mendukung kenyamanan } \\
\text { aktivitas } \\
\text { - Mendukung kebersihan dan } \\
\text { kesehatan } \\
\text { - Mendukung keindahan }\end{array}$ \\
\hline
\end{tabular}
yang akan berpengaruh kepada kesahihan hasil.

$$
C I=\frac{\lambda_{\text {maks }}-1}{n-1}
$$

Tabel 4. Alternatif pembobotan yang digunakan untuk penentuan skala prioritas

e. Perhitungan konsistensi rasio, matriks perbandingan dapat diterima apabila nilai rasio konsistensi $<0.1$

$$
C R=\frac{C I}{R I}
$$

Nilai Random Indeks (RI) tergantung ukuran matriks sebagaimana terlihat pada Tabel 5. 
Tabel 5. Hubungan antara ukuran matriks dan nilai RI

\begin{tabular}{c|c|c|c|c|c|c|c|c|c|c|c|c|c|c|c}
\hline Matriks & 1 & 2 & 3 & 4 & 5 & 6 & 7 & 8 & 9 & 10 & 11 & 12 & 13 & 14 & 15 \\
\hline RI & 0 & 0 & 0,5 & 0,9 & 1,12 & 1,24 & 1,32 & 1,41 & 1,45 & 1,49 & 1,51 & 1,48 & 1,56 & 1,57 & 1,59 \\
\hline
\end{tabular}

Pada penetapan bobot komponen/ elemen menggunakan model AHP ini, syarat penyusunan matriks perbandingan dapat diterima apabila nilai $\mathrm{CR} \leq 0,1$

\subsection{Pembobotan Indeks Kondisi Fisik Bangunan}

Pembobotan ini diperoleh dari data primer yang merupakan pengambilan data kondisi existing masing-masing komponen bangunan melalui pengamatan secara visual kemudian dikalikan dengan masing-masing bobot komponen yang diperoleh melalui pembobotan pada perhitungan Analytical Hierarchy Process (AHP).

\section{HASIL DAN PEMBAHASAN}

\subsection{Analisis Skala Prioritas berdasarkan Petunjuk Teknis Dana Alokasi Khusus (DAK) Bidang Pendidikan}

Dari data primer yang diperoleh, prioritas perawatan bangunan gedung sekolah menurut Petunjuk Teknis DAK penerapannya hanya ditinjau dari tingkat kerusakan yang diperoleh tanpa memperhatikan kriteria-kriteria lain dan juga tanpa melibatkan respond expert.

\subsection{Analisis Metode AHP}

Perhitungan bobot dimulai dari tingkat paling atas pada hierarki bangunan gedung, yaitu dimulai dari perhitungan bobot struktur bobot arsitektur dan bobot utilitas. Perhitungan ini didasarkan atas kriteria yang dipilih, yang meliputi: memberi keselamatan, memberi kenyamanan, memberi keindahan dan memberi kemudahan akses. Demikian seterusnya perhitungan ini dilakukan guna mencari bobotbobot pada hierarki bangunan gedung sesuai dengan kriterianya masing-masing. Hasil pembobotan dapat dilihat pada Tabel 5.

Hasil pembobotan dari analisis menggunakan metode AHP selanjutnya digunakan untuk menghitung pembobotan indeks kondisi bangunan.

\begin{tabular}{|c|c|c|}
\hline Komponen & Sub Komponen & Elemen \\
\hline \multirow{7}{*}{$\begin{array}{l}\text { Struktur } \\
(0.361)\end{array}$} & \multirow{2}{*}{$\begin{array}{l}\text { Struktur atap } \\
(0.295)\end{array}$} & Kuda-kuda (0.786) \\
\hline & & Gording $(0.214)$ \\
\hline & \multirow{2}{*}{$\begin{array}{l}\text { Struktur atas } \\
(0.313)\end{array}$} & Kolom (0.670) \\
\hline & & Balok (0.330) \\
\hline & \multirow{2}{*}{$\begin{array}{l}\text { Struktur bawah } \\
(0.393)\end{array}$} & Fondasi $(0.417)$ \\
\hline & & Sloof $(0.583)$ \\
\hline & \multicolumn{2}{|l|}{$\begin{array}{l}\text { Penutup atap } \\
(0.178)\end{array}$} \\
\hline \multirow{8}{*}{$\begin{array}{l}\text { Arsitektur } \\
(0.337)\end{array}$} & \multirow{2}{*}{ Plafon (0.115) } & $\begin{array}{l}\text { Rangka plafon } \\
(0.441)\end{array}$ \\
\hline & & $\begin{array}{l}\text { Penutup plafon } \\
(0.559)\end{array}$ \\
\hline & \multirow[t]{2}{*}{ Dinding (0.203) } & $\begin{array}{l}\text { Pasangan bata } \\
(0.478)\end{array}$ \\
\hline & & Plesteran (0.522) \\
\hline & \multirow{2}{*}{$\begin{array}{l}\text { Pintu \& jendela } \\
(0.695)\end{array}$} & $\begin{array}{l}\text { Pintu \& jendela } \\
(0.695)\end{array}$ \\
\hline & & Kosen $(0.305)$ \\
\hline & \multirow[t]{2}{*}{ Lantai (0.128) } & $\begin{array}{l}\text { Lantai keramik } \\
(0.837)\end{array}$ \\
\hline & & Rabat $(0.163)$ \\
\hline \multirow{2}{*}{$\begin{array}{l}\text { Utilitas } \\
(0.302)\end{array}$} & \multicolumn{2}{|l|}{$\begin{array}{l}\text { Instalasi listrik } \\
(0.622)\end{array}$} \\
\hline & \multicolumn{2}{|l|}{$\begin{array}{l}\text { Instalasi air } \\
(0.378)\end{array}$} \\
\hline
\end{tabular}

\subsection{Analisis Indeks Kondisi Fisik Bangunan}

Untuk mendapatkan bobot tingkat kerusakan bangunan maka dilakukan perhitungan indeks kondisi bangunan secara bertahap sesuai dengan susunan hierarki komponen bangunan dimulai dari Indeks Kondisi Elemen (IKE) yang merupakan komponen pada tingkat paling bawah pada struktur hierarki dan meningkat hingga diperoleh indeks kondisi gabungan. Contoh perhitungan dapat dilihat pada Tabel 6.

Sesuai dengan bobot masing-masing komponen dan pengelompokannya, maka Indeks Kondisi Komponen (IKK) struktur dapat dihitung sebagai berikut:

IKK struktur

$=(64,44 \times 0.295)+(94.98 \times 0.313)+(100 \times 0.393)$ $=87.95 \%$

Dengan cara yang sama diperoleh indeks kondisi untuk komponen-komponen bangunan gedung lainnya. Dari hasil analisis dapat dilihat pada Gambar 3 sampai dengan Gambar 5 . 
Tabel 6. Perhitungan Indeks Kondisi Sub Elemen (IKSE)

\begin{tabular}{|c|c|c|c|c|c|c|}
\hline$\frac{\tilde{D}}{\frac{0}{0}}$ & 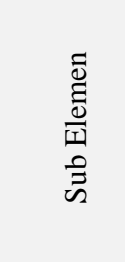 & 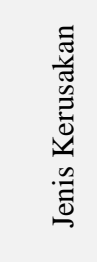 & 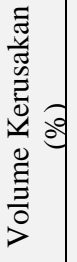 & $\frac{V}{I}$ & 之 & 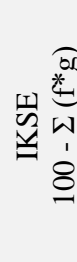 \\
\hline$a$ & $b$ & $c$ & $e$ & $f$ & $g$ & $h$ \\
\hline \multirow{4}{*}{$\begin{array}{l}\text { Struktur } \\
\text { atap }\end{array}$} & \multirow{2}{*}{$\begin{array}{l}\text { Kuda- } \\
\text { kuda }\end{array}$} & lapuk & 50 & 0.7 & 38 & \multirow{2}{*}{62.0} \\
\hline & & lendut & 50 & 0.3 & 38 & \\
\hline & \multirow{2}{*}{ Gording } & retak & 0 & 0 & 0 & \multirow{2}{*}{73.4} \\
\hline & & lendut & 35 & 0.7 & 38 & \\
\hline \multirow{4}{*}{$\begin{array}{l}\text { Struktur } \\
\text { atas }\end{array}$} & \multirow{2}{*}{ Kolom } & $\begin{array}{l}\text { kerop } \\
\text { os }\end{array}$ & 0 & 0 & 0 & \multirow[t]{2}{*}{100.} \\
\hline & & retak & 0 & 0 & 0 & \\
\hline & \multirow{2}{*}{ Balok } & retak & 50 & 0.4 & 38 & \multirow{2}{*}{84.8} \\
\hline & & lendut & 0 & 0 & 0 & \\
\hline \multirow{4}{*}{$\begin{array}{l}\text { Struktur } \\
\text { bawah }\end{array}$} & \multirow{2}{*}{ fondasi } & pecah & 0 & 0 & 0 & \multirow{2}{*}{100.} \\
\hline & & retak & 0 & 0 & 0 & \\
\hline & \multirow{2}{*}{ Sloof } & lendut & 0 & 0 & 0 & \multirow{2}{*}{100.} \\
\hline & & pecah & 0 & 0 & 0 & \\
\hline
\end{tabular}

Tabel 7. Perhitungan Indeks Kondisi Elemen (IKE)

\begin{tabular}{|c|c|c|c|c|}
\hline$\frac{\tilde{\Xi}}{\stackrel{\Xi}{ \pm}}$ & 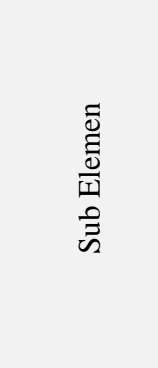 & 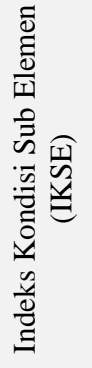 & 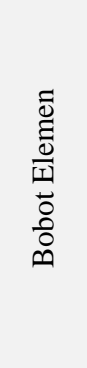 & 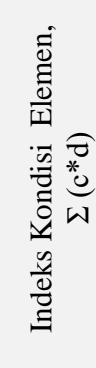 \\
\hline $\mathrm{a}$ & $\mathrm{b}$ & $\mathrm{c}$ & $\mathrm{d}$ & $\mathrm{e}$ \\
\hline \multirow{2}{*}{$\begin{array}{l}\text { Struktur } \\
\text { atap }\end{array}$} & Kuda-kuda & 62 & 0.786 & \multirow{2}{*}{64.44} \\
\hline & Gording & 73.4 & 0.214 & \\
\hline \multirow{2}{*}{$\begin{array}{c}\text { Struktur } \\
\text { atas }\end{array}$} & Kolom & 100 & 0.670 & \multirow[t]{2}{*}{94.98} \\
\hline & Balok & 84.8 & 0.330 & \\
\hline \multirow{2}{*}{$\begin{array}{l}\text { Struktur } \\
\text { bawah }\end{array}$} & fondasi & 100 & 0.417 & \multirow[t]{2}{*}{100.00} \\
\hline & Sloof & 100 & 0.583 & \\
\hline
\end{tabular}

Indeks Kondisi Bangunan

di Kecamatan Sananwetan

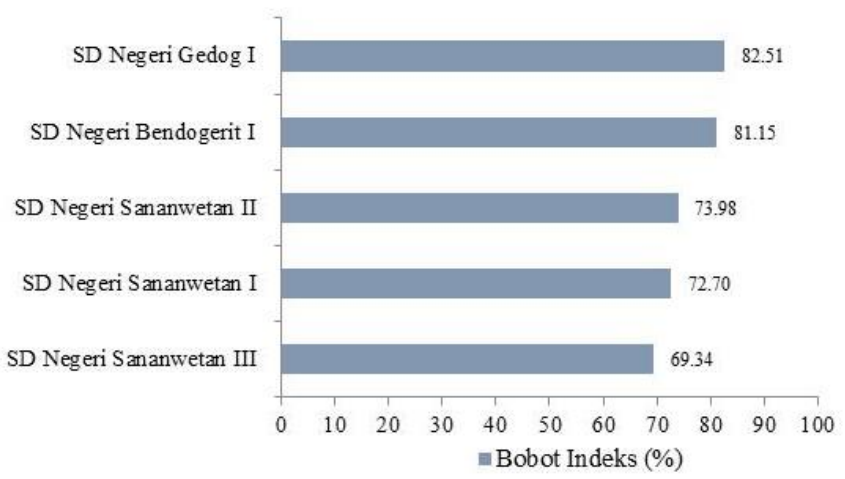

Gambar 3. Grafik indeks kondisi fisik bangunan sekolah di Kecamatan Sananwetan

\section{Indeks Kondisi Bangunan di Kecamatan Sukorejo}

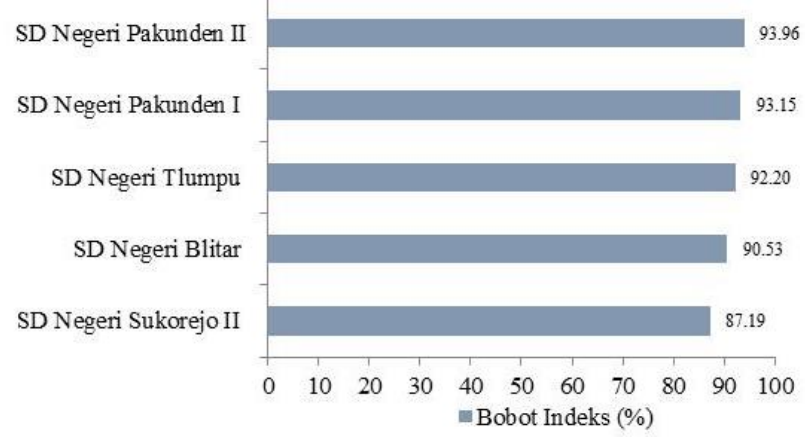

Gambar 4. Grafik indeks kondisi fisik bangunan sekolah di Kecamatan Sukorejo

Indeks Kondisi Bangunan di Kecamatan Kepanjenkidul

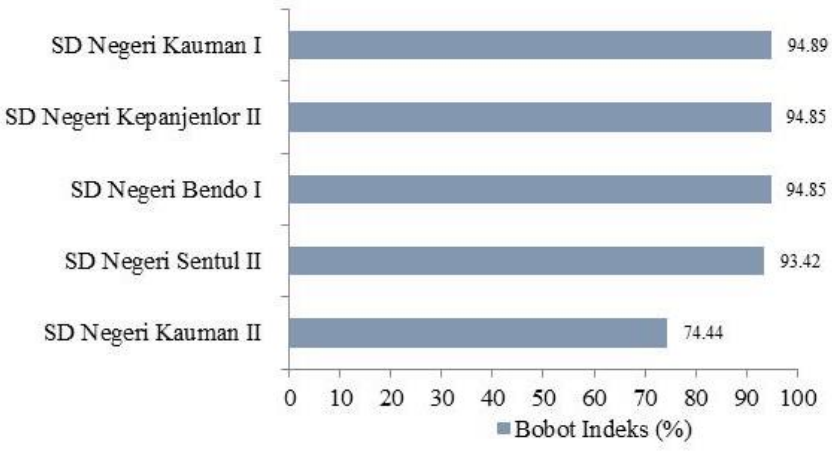

Gambar 5. Grafik indeks kondisi fisik bangunan sekolah di Kecamatan Kepanjenkidul 
Bobot indeks kondisi fisik bangunan sekolah dasar di Kecamatan Sananwetan Kota Blitar setelah diurutkan dari indeks kondisi yang paling rendah yaitu bangunan sekolah SD Negeri Sananwetan III dengan nilai 69.34\% dapat diartikan bahwa kerusakan yang terjadi pada bangunan gedung sebesar 100-69.34= $30.64 \%$. Selanjutnya tingkat kerusakan bangunan secara berurutan dari yang paling besar yaitu SD Negeri Sananwetan I (27.3\%), SD Negeri Sananwetan II (26.02\%), SD Negeri Bendogerit I (18.85\%) dan SD Negeri Gedog 1 (17.49\%).

Indeks kondisi bangunan pada skala 69.34\% menjelaskan bahwa bangunan sekolah tersebut dalam keadaan sedang dan mulai terjadi deteriorasi atau kerusakan namun tidak mempengaruhi fungsi struktur bangunan secara keseluruhan.

\subsection{Perbandingan Analisis DAK dengan metode AHP dan Indeks Kondisi Fisik.}

Hasil perhitungan skala prioritas perawatan bangunan gedung sekolah dengan menggunakan bobot yang diperoleh berdasarkan metode AHP lebih terperinci karena memperhatikan banyak kriteria yang merupakan identifikasi dari kerusakan bangunan, sedangkan analisis DAK hanya ditinjau dari segi kerusakan bangunan saja tanpa memperhatikan banyak kriteria-kriteria pendukung bangunan lainnya.

\section{KESIMPULAN DAN SARAN \\ 5.1 Kesimpulan}

Kesimpulan yang dapat diambil dari hasil penelitian ini adalah sebagai berikut:

1. Penentuan skala prioritas penanganan perawatan bangunan gedung sekolah berdasarkan analisis DAK No. 04/D/P/2016 tentang Petunjuk Pelaksanaan DAK Bidang Pendidikan Sekolah Dasar/Sekolah Dasar Luar Biasa masih kurang valid karena penilaian bernilai subjektif dan belum melibatkan ahli teknik bangunan.

2. Analisis berdasarkan metode AHP, kriteria yang berpengaruh dalam penentuan prioritas dalam penentuan prioritas pemeliharaan gedung sekolah dasar negeri di Kota Blitar adalah kriteria struktur dengan bobot $36,10 \%$, komponen arsitektur $33,70 \%$ dan komponen utilitas $30,20 \%$.
Penilaian kondisi fisik bangunan sekolah dasar negeri di Kota Blitar yang paling rendah adalah sebesar $69.34 \%$, maka dapat dinyatakan dalam keadaan sedang dan mulai terjadi deteriorasi atau kerusakan namun tidak mempengaruhi fungsi struktur bangunan secara keseluruhan. Diperlukan analisis ekonomi alternatif perbaikan untuk menetapkan tindakan yang tepat.

3. Urutan prioritas pemeliharaan bangunan gedung sekolah dasar negeri di Kota Blitar dikelompokkan dalam 3 (tiga) kecamatan, yaitu tingkat kerusakan di (1) Kecamatan Sananwetan adalah SD Negeri Sananwetan III (30.64\%.), SD Negeri Sananwetan I (27.3\%), SD Negeri Sananwetan II (26.02\%), SD Negeri Bendogerit I (18.85\%), SDN Gedog 1 (17.49\%); (2) Kecamatan Sukorejo yaitu SD Negeri Sukorejo II (12.81\%), SD Negeri Blitar (9.47\%), SD Negeri Tlumpu (7.8\%), SD Negeri Pakunden I (6.85\%) dan SD Negeri Pakunden II (6.04\%); (3) Kecamatan Kepanjenkidul yaitu SD Negeri Kauman II (25.56\%), SD Negeri Sentul II (6.58\%), SD Negeri Bendo I (5.15\%), SD Negeri Kepanjenlor II (5.15\%) dan SD Negeri Kauman I (5.11\%).

\subsection{Saran}

Agar penentuan skala prioritas pemeliharaan bangunan gedung sekolah dasar bisa lebih sempurna, maka disarankan:

1. Dalam menentukan skala prioritas perawatan bangunan sekolah di Kota Blitar, pemerintah daerah sebaiknya mempertimbangkan metode AHP dan Indeks Kondisi Fisik selain berdasarkan Petunjuk Teknis Dana Alokasi Khusus (DAK) bidang Pendidikan. Adapun pertimbangannya yaitu metode AHP dapat mengombinasikan berbagai aspek dan kriteria yang dilakukan dengan pembobotan berdasarkan tingkat kepentingan sehingga hasil urutan prioritas penanganan bangunan yang dihasilkan lebih representatif.

2. Perlu adanya tim teknis yang sesuai kompetensi pada bidangnya yang bertugas sebagai pendamping dalam hal perencanaan, pengawasan dan pelaksanaan selama proses konstruksi.

3. Perlunya pemeriksaan kerusakan bangunan dengan alat yang lebih akurat (hammer test, ultrasonic-pulse velocity).

4. Perlu adanya pengembangan suatu program aplikasi software jaringan antara setiap 
sekolah dengan dinas pendidikan agar proses penilaian kondisi bangunan lebih cepat.

\section{DAFTAR PUSTAKA}

[1] Peraturan Direktur Jenderal Pendidikan Dasar Menengah, Kementerian Pendidikan dan Kebudayaan No.04/ D/P/2016 tentang Petunjuk Pelaksanaan Dana Alokasi Khusus Bidang Pendidikan Sekolah Dasar/Sekolah Dasar Luar Biasa.

[2] Permen PU No.24/PRT/M/2008 tentang Pedoman Pemeliharaan dan Perawatan bangunan Gedung

[3] Peraturan Menteri Pendidikan dan Kebudayaan Republik Indonesia No.81 tahun 2015 tentang Petunjuk Teknis Dana Alokasi Khusus Bidang Pendidikan SD/SDLB.

[4] Saaty, T.L.,1986, Proses Hirarki Analitik untuk Pengambilan Keputusan dalam Situasi yang Kompleks, Jakarta: PT Pustaka Binman Pressindo. 